conditions causing uneasiness, for which relief is sought in some faulty posture of standing, sitting, lying, or all three. These are, however, exceptional, and rarely produce other than slight curves. In all curvatures primarily lumbar rotation plays a less prominent part than in dorsal curves. In certain cases it is very slight, in others more marked in proportion to the deviation, but is never so considerable or so important as it is in most cases of dorsal curvature. In another paper I shall describe the diagnosis and treatment of loin curvature.

Wimpole-street, W.

\section{ON SOME}

\section{RESULTS OF CICATRISING PROCESSES IN THE NEIGHBOURHOOD OF THE PORTAL FISSURE.}

BY HENRY F. A. GOODRIDGE, M.D., F.R.C.P., SENIOR PHYSICLAN TO THE ROYAL UNITED HOSPITAL, BATE. (Concluded from p. 1227.)

THE second case exhibits cicatrisation bringing about in the same way a different result; as will be observed, it has an additional connecting link with the first case.

J. T-, aged eighty, was admitted on May $25 \mathrm{th}, 1875$. She stated that through the whole of her life up to the last winter but one she never had any illness; she then had what she called "the cold shivers" with slight cough. Her present attack commenced between four and five weeks previously with pain over the region of the liver, shooting through to the right shoulder blade; at the same time she became jaundiced. Her bowels were confined, the stools being light-coloured; and her urine was very dark. She had vomited three or four times during the last week, and her appetite had failed. On admission, she exhibited marked jaundice, but the pain had pretty well subsided. Her temperature in the axilla was $97^{\circ}$; pulse 68 , radial artery senile; respiration 32 ; and tongue moist, but coated with whitish fur. Her bowels had not been open since the 23rd, when the stool, it was said, was pale; the urine was acid, sp. gr. 1017, very dark, and on testing showed the presence of bile pigment. She had some itching of her skin.

May 26th: She had slept well. The bowels had acted slightly, the stool being clayey. Her temperature was $97.4^{\circ}$, pulse 64 , and respiration 28 . The liver extended to near the umbilicus; it did not feel hard, and presented no inequalities of surface except at the extreme right, where there seemed to be a small hard nodule on the convex surface; it was near the edge, which could be distinctly felt all along, but was not thickened or rounded. There was apparent distension of the ascending colon, a feeling as of a firm tube extending vertically under the right rectus muscle.-28th: She had had good nights, and her appetite was improved. When she had taken a little wine that was ordered she said it gave her pain in the stomach. She vomited once in the evening.-June 1st: She had had no further sickness, and had no pain whatever. She was sleeping well and taking her food well. Her temperature was $97^{\circ}$, pulse 56 , and respiration 24 . A little brandy-andwater, which was substituted for the wine, she said she could not get on with.-15th: She had had some bronchial catarrh the last few days. Her bowels were open about once daily; the stools had continued clayey, but were now of a slate colour. She passed upwards of thirty ounces of urine in the twenty-four hours. The jaundice was much as before.-20th: She had vomited several times to-day.25th: There had been no return of vomiting. Her cough had continued troublesome. She had no pain. Her temperature was $96^{\circ}$, pulse 72, and respiration 32. Her bowels were open daily, the stools being still slate-coloured. The jaundice.was much as before,-26th : About 3 A.M. she began to vomit black coffee-ground-like matter. At 9 this had amounted to upwards of two pints. She had no pain, but felt exhausted; her pulse was 116 and very feeble. There was a little tenderness on pressure in the epigastric region, none elsewhere. In the vomited matters were numberless red blood-discs. The patient became much collapsed and died the same evening.

Necropsy, forty-four hours after death.-On opening the abdomen the liver presented nothing remarkable, except near the margin of the right half of the right lobe, in the situation where was observed the hard nodular feel during life. Here the convex surface exhibited an opaque yellowish white puckered look; in fact, the appearance of a large cicatrix with some amount of central depression. The texture was dense and indurated, and this condition was felt to extend through the entire thickness of this part of the organ. Underneath was a thick, tough, and pretty extensive adhesion of the transverse colon, so that only by the knife could the intestine be separated. Its lumen was slightly diminished in consequence, and on opening it there was found some puckering of the mucous surface, but no ulceration. On making a section through the indurated portion of the liver here, the same cicatricial character was observable. Corresponding somewhat in situation to the gallbladder was a small cyst-like cavity that would contain about one fluid drachm; a little mucoid matter was in it; there was no trace of duct. The opaque tissue gradually and in a somewhat radiating manner passed into the surrounding hepatic texture. The capsule could not be separated over this part. There were also some diaphragmatic adhesions and thickening of the capsule, but nowhere else in the organ was there any appearance similar to that described. The hepatic duct, as it issued from the liver, was quite pervious; so also was the common bile duct at its entrance into the duodenum, but even a No. 1 catheter would not pass through the latter. The liver weighed $40 \mathrm{oz}$; its parenchyma generally was coarse. No gall-stone wes found anywhere. The stomach was considerably dilated. It contained a quantity of thin melanic fluid like what had been vomited during life. Near the small curvature on the posterior wall, but not so near the pylorus, was a largish ulcer, which reached to the peritoneal coat, and was distinctly terraced. Just within its margin, which presented no thickening, was the open mouth of an artery, evidently a branch of the coronary. The kidneys were somewhat granular; the two together weighed $6 \mathrm{oz}$. Nothing important was found elsewhere.

Now, the cicatricial appearances in this woman's liver bad prima facie very much the characters of a syphilitic lesion; I was disposed, however, to think that they were due to an old suppurative inflammation of the gall-bladder, perhaps connected with gall-stones, which had discharged by a fistulous opening into the transverse colon. Be that as it may, the origin of the cicatricial tissue does not so much concern us as its presence, and its presence in quantity, in the substance and on the under surface of this part of the organ; though here, as in the case of A. M- -.., the products of adhesive local peritonitis were clearly more or less blended with it. Caught apparently in one part of its course within the fibrous bands of this contracting tissue, the common bile duct became constricted, and jaundice ensued. As to the ulcer in the stomach, we may remark in passing that possibly it owed its origin to arterial degeneration, which is recognised by authorities as a cause of gastric ulcer in old people. The same condition might also explain how it was that the hæmatemesis was not of that florid and instantaneously fatal character that the size of the gaping artery would have led one to expect.

The products of adhesive inflammation have been above referred to as having had a share in bringing about the pathological events under consideration. These products and cicatricial tissue, we know, are histologically closely allied forms of fibrous connective tissue, and they possess alike the property of contraction. In the cases before us the share taken by the inflammatory products was a subordinate one; but in some instances, as, from the facts just noticed, and from our acquaintance with the operation of such products on a larger scale elsewhere, we might well anticipate, they show themselves capable per se of inducing similar results. "Now and then the fibroid tissue developed in the portal fissure from the products of inflammation produces constriction of the bile duct or portal vein." 1

It is not unimportant, I think, to discriminate between cases such as we have been considering and those where vessels, ducts, \&c., are compressed by the gradual stuffing by adventitious products of the spaces wherein they run Thus, in a case of lymphadenoma of the retroperitoneal glands under my care, "the disease had attacked also the portal glands, and a considerable mass was found deep between the liver and stomach, in which the vessels in the portal fissure were embedded. On cutting transversely

I Murchison on Diseases of the Liver, 3rd edition, p. 310 C C 2 
through the mass, the common bile duct, the hepatic artery, and the portal vein were divided, their mouths being quite patulous and their calibre undiminished."2 The tissue here possessing no marked contractile property, the vessels, though embedded in the same, did not suffer. At a further stage of the growth, of course, compression would ensue, with narrowing or occlusion of one or more vesselo, according to the resistance they might respectively offer. But then the modus operandi would be that of a pretty uniform constriction, comparable to the slow tightening of a ligature. Not so, however, in the class of case dealt with in this paper. We use the terms contraction and constriction in discussing the same, but, as has been pointed out, the contraction of cicatricial tissue in cases of this kind is, strictly speaking, a concentric retraction, a shrinking which takes place in all dimensions, and is directed in radial lines towards a centre or centres which are determined by the cunditions of the original lesion, and the foci, one or more as the case may be, of tissue destruction. Hence the effect on vessels, ducts, \&c.; traversing the area of cicatrisation, is rather an irregular traction or torsion than a uniform constriction as in the former instance. And hence also it happens, that in the same cicatricial area, while one vessel is implicated, another is not at all so, or only in a minor degree. Bath.

\section{THE RELIEF OF THE MORPHIA CRAVING BY SPARTEINE AND NITRO-GLYCERINE. ${ }^{3}$}

BY OSCAR JENNINGS, M.D., M.R.C.S., ELECTRIGAL PHYSICIAN TO THE CLINIQUE OF ST. ANNE.

IN a note on the Condition of the Pulse in Morphinomanis presented by Professor Ball and myself at the French Academy of Sciences, ${ }^{4}$ we discussed the mechanism of the morphis craving, and showed that during the period of privation there is ischæmia of the general circulation. An injection of morphia administered at this time causes a disappearance of the psycho-somatic suffering which constitutes the craving, and is followed by a restoration of the pulse. In a second communication to the Academy of Medicine ${ }^{5}$ we stated that we had found, moreover, that the morphia craving can be appeased by the use of other medicines having the property of restoring the pulse in a similar manner. We had experimented extensively with two agents of the kind on patients at Laennec, St. Anne, and in our private practice. The first of these is sparteine. "We thought it would be preferable to try heart tonics, and strengthen the action of this organ in moments of weakness. To this end we have employed sulphate of sparteine, which fulfils most of the conditions, and can easily be administered by hypodermic injections. We watch for the moment of weakness as indicated both by plateau in the sphygmographic tracings and by the intimate sensations of the patient. At this moment we administer an injection of from two to four centigrammes, which may be repeated when necessary, and at the expiration of a few minutes we see the pulse strengthen and the craving disappear. To use the words of one of our patients, 'the medicine gives heart.' This expresses in familiar language a physiological truth of which the sphygmograph confirms the absolute exactitude ...... Another medicine which procures a passing relief of the symptoms is nitro-glycerine. Its effects, very similar to those of sparteine as regards the point in question, are at the same time much more rapid and much more ephemeral."

Since the preceding lines were written $I$ have administered sparteine and nitro-glycerine repeatedly in fourteen different cases, and I feel convinced that in these agents, properly administered, we possess a means which will enable - any morphia habitué earnestly desirous of leaving off his intemperance to carry the process of weaning to a successful issue. All morphia habitués have from time to time a maudling hysterical desire to give up the practice, but this vanishes at the tirst feeling of discomfort. For such cases there can be no suppression without restraint, and a result

Fxtract from the post-mortem notes.

3 Read at the Sociêtê Médicale de l'mlysêe of Paris.

4 Des Modifications da Pouls dans la Morphinomanie. Comptes Rendus de l'Académie des Sciences. March, 1887.

Considerations sur le Traitement de la Morphinomanie. Bulletin de l'Académie de Médicine. March, 1887. so obtained is very unsafe for the future. Deprived of their morphia in an asylum, patients are not thereby cured of the craving. They have been forced by a compulsion, which bas provivionally taken the place of their will, and a morphinomaniac is no more cured of his passion by this forced deprivation than is the dipsomaniac by abstinence from alcohol during a certain time. A relapse generally occurs as soon as the patient has recovered his liberty. But there are morphia habitués who honestly loathe their thraldom, and who would do anything short of the impossible to break through it. Very few medical men seem to realise the nature and intensity of the euffering which accompanies the privation from morphia, and upon which they are occasionally called upon to advise. A gentleman, whose case I related in the Encéphale of Marcb, 1887, and who was cured of the habit by inhibition of the craving, was informed by some of the consultants he had seen that the confirmed babit of morphia was incurable. I believe it is the writer of the section on Morphinism in Ziemssen's Cyclopædia who is responsible for this opinion. But the greater number of his previous advisers liad been of opinion that all that was necessary to cure him of the habit was for him to "throw away his syringe and solution, and just make up his mind not to get any more."

Now, the truth lies between these extremes of theoretical error and practical ignorance. Some morphia habitués would have sufficient resolution to wean themselves of the practice of the terrible distress resulting from privation if this could be alleviated in a certain measure; and it is to these that I refer when I say that those who are earnestly desirous of breaking off the habit can be enabled to do so by the help of sparteine and nitro-glycerine. To be properly administered the remedies mentioned must only be used when really needed, and should not therefore be at the patient's disposa]. The only results I have ever seen of giving succedanea to morphinomaniacs has been to complicate the first disease by a second, and very often a much more dangerous, intemperance. And just as I have seen morphia habitués acquire an additional craving for alcohol, chloral, cocaine, and other drugs of the kind, so I think it quite possible that the reckless and uncontrolled administration of the medicines I recommend may give rise to an artificial desire for them-a possibility foreshadowed by Dr. Murrell in his work on Nitro-Glycerine in Angina Pectoris. Given at the right moment, and in suitable doses, spartsine and nitro-glycerine, either separately or together, form an admirable means of relieving the morphia craving, and the only modification I have to make in the statement quoted above is with reference to the intensity and duration of the action of nitro-glycerine. Further, experience has taught $m \theta$ that the effect of nitro-glycerine is most satisfactory and persistent in those cases where there is a predominance of the "yearning" over the "craving" - that is to say, in which the psychical symptoms are more distressing than those of a somatic order. When, on the other hand, there is more physical craving than morphine-nostalgia, as I have termed it, the use of sparteine, which is a tonic to the circulation, gives better results than nitro-glycerine alone, which I take to be nervo-inhibitory. What, however, I would especially insist upon in the present note, is that, in the simultaneous administration of the two drugs, the one by subcutaneous injection and the other placed upon the tongue, we possess a perfect remedy for the morphia craving in its double psycho-somatic modality. Some patients, as would naturally be expected, say that one or both drugs fail to give them relief; but, as far as my experience goes, these are persons who have no real intention of giving up their morphia. Indeed, all they desire is to be allowed to indulge without interference in their vice. But those who have retained sufficient will to resist the first promptings of a capricious impulse will find that the true morphia bunger can be entirely appeased by sparteine and nitro-glycerine. taken when there is a genuine necessity. The subjoined sphygmographic tracings show better than a lengthened description the relative values of the two remedies.

Tracings Nos. 1 and 2 were taken from a patient at Laennec, whose case is partially reported in my little work on Morphinomania ${ }^{6}$ No 1 being before, and No. 2 after, an injection of morphine; the first shows the state of craving, the second that of satisfaction. No. 3 is a tracing of the same pulse after a hypodermic injection of sparteine instead of morphine. The patient having stated that the sparteine 